\title{
Assessing insect responses to climate change: What are we testing for? Where should we be heading?
}

To understand how researchers are tackling globally important issues, it is crucial to identify whether current research is comprehensive enough to make substantive predictions about general responses. We examined how climate change affecting insects is being assessed, what factors are being tested and the localities of studies, from 1703 papers published between 1985 and August 2012. Most published research (64\%) is generated from Europe and North America and being dedicated to core data analysis, with $29 \%$ of the studies analysed dedicated to Lepidoptera and 22\% Diptera: which are well above their contribution to the currently identified insect species richness (estimated at 13\% and 17\% respectively). Research publications on Coleoptera fall well short of their proportional contribution (19\% of publications but 39\% of insect species identified), and to a lesser extent Hemiptera, and Hymenoptera. Species specific responses to changes in temperature by assessing distribution/ range shifts or changes in abundance were the most commonly used methods of assessing the impact of climate change on insects. Research on insects and climate change to date is dominated by manuscripts assessing butterflies in Europe, insects of economic and/ or environmental concern in forestry, agriculture, and model organisms. The research on understanding how insects will respond to a rapidly changing climate is still in its infancy, but the current trends of publications give a good basis for how we are attempting to assess insect responses. In particular, there is a crucial need for broader studies of ecological, behavioural, physiological and life history responses to be addressed across a greater range of geographic locations, particularly Asia, Africa and Australasia, and in areas of high human population growth and habitat modification. It is still too early in our understanding of taxa responses to climate change to know if charismatic taxa, such as butterflies, or disease vectors, including Diptera, can be used as keystone taxa to generalise other insect responses to climate change. This is critical as the basic biology of most species is still poorly known, and dominant, well studied taxa may show variable responses to climate change across their distribution due to regional biotic and abiotic influences. Indeed identifying if insect responses to climate change can be generalised using phylogeny, functional traits, or functional groups, or will individual populations and species exhibit 
idiosyncratic responses should be a key priority for future research. 
$1 \quad$ Nigel R. Andrew ${ }^{*}, \Psi$, Sarah J. Hill ${ }^{\Psi}$, Matthew Binns ${ }^{*},{ }^{\prime}$, Md. Habibullah Bahar ${ }^{*}, \delta$

2 Emma V. Ridley ${ }^{\Omega}$, Myung-Pyo Jung ${ }^{*}$, , Chris Fyfe ${ }^{\Psi}$, Michelle Yates ${ }^{*}, \Psi$, and

3 Mohammad Khusro*

4

$5 \quad{ }^{*}$ Centre for Behavioural and Physiological Ecology, Zoology, University of New

6 England, Armidale, NSW, Australia 2351

$7{ }^{\Psi}$ School of Environmental and Rural Sciences, University of New England,

8 Armidale, NSW, 2351, Australia

$9 \Omega$ Department of Biology, University of York, York, YO10 5DD, UK

10 ' ${ }^{\ni}$ Department of Agricultural Biology, National Academy of Agricultural Science,

11 Suwon, 441-707, South Korea.

12

${ }^{\delta}$ Saskatoon Research Centre, Agriculture and Agri-Food Canada, Saskatoon,

13 SK, S7N 0X2, Canada.

14 Correspondence: Nigel Andrew, Centre for Behavioural and Physiological

15 Ecology, Zoology, University of New England, Armidale, NSW, Australia 2351,

16 Australia. tel. +61 26773 2937, fax +61 26773 3814, E-mail:

17 nigel.andrew@une.edu.au

18 


\section{Introduction}

Attempts to assess and predict the biological impacts of climate change, are

21 two of the most important and intensive research endeavours of our time (Parmesan

22 \& Yohe 2003; Root et al. 2003; IPCC 2007; Loarie et al. 2009). The knowledge base

23 for the information relating to biological impacts of climate change is highly

24 integrative, covering broad disciplines of behaviour, biogeography, ecology,

25 evolution, genetics, genomics, phenology and physiology (Hoffmann, Sørensen \&

26 Loeschcke 2003; Andrew \& Hughes 2004; Andrew \& Hughes 2005; Parmesan 2007;

27 Clusella-Trullas et al. 2008; Williams et al. 2008; Kellermann et al. 2009; Chown et

28 al. 2010; Andrew, Hart \& Terblanche 2011; Burthe et al. 2011). In spite of the large

29 amounts of data that are being accumulated addressing biotic responses of

30 organisms to climate change, we are still a long way from understanding whether

31 there are generalities across space, taxa, and time in terms of responses and

32 adaptability to rapid change, or whether most organisms will respond

33 idiosyncratically, and the implications of this on species interactions both within and

34 among trophic levels. In addition, the lack of long-term records (> 50 years) means

35 that much of the research today is being conducted without a strong baseline to

36 assess species and community responses to climate change, with the exception of a

37 few charismatic species in some regions (Woodward 1987; Keatley et al. 2002;

38 Peñuelas, Filella \& Comas 2002; Brereton et al. 2011; Moore, Thompson \& Hawkins

39 2011; Rafferty \& Ives 2011; Wilson \& Maclean 2011; Andrew 2013; Andrew \&

40 Terblanche 2013).

41 Insects are the most dominant groups of organisms on the planet in terms of 42 species richness, abundance and biomass (Gullan \& Cranston 2010). The crucial 43 roles that they play in all terrestrial and many aquatic ecosystems, are well 
44 understood and are critical for ecological function and food web structure (Price et

45 al. 2011). However, our understanding of individual species is extremely limited.

46 Most species of insects are yet to be identified (Yeates, Harvey \& Austin 2003;

47 Cranston 2010), and many have had little, if any, biological information collected on

48 them, yet many species are potentially highly vulnerable to the impacts of climate

49 change and extinction (Dunn 2005). Nevertheless, there has been a substantive

50 amount of research dedicated to assessing potential insect responses to

51 human-induced climate change. One of the major challenges we face is to determine

52 the impacts of climate change on insects, broadly, and gather enough information to

53 develop mechanistic models on single species (Angilletta 2009; Kearney et al. 2009)

54 and species interactions (e.g. game theory Mitchell \& Angilletta 2009) across a range

55 of species to assess multi-trophic community responses to climate change.

Assessing how the research community is attempting to measure climate

57 change impacts can be done by identifying research agendas within publications and

58 identifying trends and gaps across published literature. Here we assessed published

59 research on climate change and insects to assess the type of research being carried

60 out, its geographic location and identify the Orders, variables and factors being

61 tested. Our intention was not to review the findings of the studies themselves, as has

62 been done by successive high profile publications and meta-analyses (Walther et al.

63 2002; Hughes 2003; Parmesan \& Yohe 2003; Root et al. 2003; Parmesan 2006;

64 Williams et al. 2008; Loarie et al. 2009), but to identify questions posed and

65 assumptions made in the published literature on insect responses to climate change. 
A literature search was conducted on all available published literature up to the

$692^{\text {nd }}$ August 2012 in Scopus (www.scopus.com) for literature with the keywords: "clim*

70 change and insect", "clim change and [each of the insect order names and generally

71 used common names]". Citations and abstracts were downloaded for 4704 studies.

72 Studies that had these keywords ranged in years from 1924 to online early

73 publications (August 2012). Each abstract was then examined to determine if it was

74 appropriate for further assessment, and a PDF reprint was then downloaded. Scopus

75 also adds keywords in addition to the authors' keywords, with many articles not

76 actually referring to climate change, in any part of their study. If climate change (or

77 equivalent term) was not referred to in the study (abstract or main body) it was not

78 included in the assessment. The number of publications was then culled down to

791703 ranging in years from 1985 to online early ( $2^{\text {nd }}$ August 2012). If studies were

80 deemed appropriate, a range of information was extracted as shown in Table 1.

81 Number of species in each order that have been formally identified as of 2010 was

82 generated from Zboroski \& Storey (2010).. The papers assessed and data extracted

83 was uploaded onto FigShare http://dx.doi.org/10.6084/m9.figshare.105599.

\section{Results and Discussion}

85

Since the mid-1990's there has been a rise in climate change and insect related

86 publications relative to previous years (Figure 1), with a substantive increase in

87 2006. By early August 2012, 127 publications had already been published in that

88 year, so it is expected that the increasing trend will continue for the remainder of

892012. 
91 Coleoptera (Figure 2a).When the number of studies were compared to the identified species richness within each Order, Lepidoptera, Diptera, Orthoptera, Collembola, and Odonata have a proportionally higher percentage of papers assessing their responses to climate change relative to number of species identified, whilst Coleoptera, Hymenoptera, and Hemiptera have a proportionally lower percentage of papers assessing their responses to climate change relative to number of species identified. Lepidoptera were most commonly studied Order in 'data' studies, 'modeling' studies, 'anecdotal' and 'desktop' studies (Figure 2b). For 'review' studies, 'multiple' Orders were the most dominant.

Climate change research assessing insects was most dominant in Europe and

101 North America (Figure 3). Lepidoptera were by far the most dominant Order studied 102 in Europe (Figure 3a), and most dominant in North America (Figure 3b), as well as in 103 Asia (but with a similar proportion of studies published on Diptera; Figure 3d). In 104 Australia/ Oceania, Africa, and South America, Diptera were the most highly studied 105 Order (Figure 3e-g). When studies were conducted across a few regions ('variety'), 106 generally multiple Orders were assessed (Figure 3h). When no geographic region was identified, the specific Orders assessed were also not clearly identified (Figure 108 3c).

Temperature was the most studied climate change factor (40\% of publications;

110 Figure 4). Surprisingly, the second most dominant climate change factor in studies 111 was 'non specific' (27\%), indicating that many studies mentioned climate change but 112 did not identify a specific aspect which elicited a biotic response. The third most 113 common factor assessed was moisture (14\%), and the fourth was those assessing 114 more than two climate change drivers (variety; 10\%), including combinations of 
115 temperature, moisture, carbon dioxide, ozone, and UVB among others. Evolutionary

116 changes, other abiotic predictors (such as UVB, ozone) and host plant changes (ie

117 indirect changes to insects) were tested in a relatively small number ( $4 \%$ in total) of

118 studies. Individual insect species publications were the most common (47\% of

119 publications), followed by insect/ plant publications (28\%) (Figure 4a). In terms of

120 publication type, data papers (56\% of publications), dominated all predictor

121 categories, with reviews second most common in 'non-specific' predictor papers,

122 whereas modelling papers ( $17 \%$ of total publications) were more prevalent in papers

123 dealing with temperature, moisture and a variety of predictors (Figure 4b). Most

124 studies conducted in native habitat assessed temperature changes ( $17 \%$ of total

125 publications; Figure 4c).

The variables that were used to measure insect responses to climate change in

127 the published literature could be broken into four groups (Figure 5). Most

128

publications on insect responses to climate change (more than 390 publications in

each category, Group A) assessed changes in distribution or range shift, changes in

abundance and interactions (such as herbivory, predation, and parasitism). The

second group of publications (Group B, above 250 and less than 310 publications

each) assessed assemblage composition changes and phenology, and Group C

133 (above 175 and less than 200 publications each) assessed insect physiology,

134 development time, and survival. Group D (less than 150 publications each) included

carried out (non-specific), as well as assessments of genetics, behaviour, morphology, body weight changes, and other life history traits.

139 Figure 6a) or where habitat was unspecified (28\%: Figure 6b). Forestry and 
140 agricultural habitats had substantially less studies (15\% and $12 \%$ respectively;

141 Figures $6 \mathrm{c}$ and d) followed by studies assessing human interactions with insects and

142 climate change (Figure 6e), and livestock and vertebrate animals (Figure 6f). In both

143 native habitats and habitats not defined ('non specific'), Lepidoptera were the most

144 dominant taxa assessed, followed by a range of taxa including Diptera, Coleoptera,

145 and multiple taxa. In agricultural systems, Hymenoptera, Diptera, Lepidoptera,

146 Coleoptera and multiple taxa dominated most studies. In Forestry habitats,

147 Coleoptera dominated, followed by Lepidoptera, Diptera and Collembola. In studies

148 assessing human interactions with insects, Diptera dominated, as they did with

149 studies on livestock and vertebrate animals. It is not surprising that there is a relative

150 bias towards some groups such as Lepidoptera (mainly butterflies), and Diptera

151 (primarily Drosophila) due to the primarily role that they play in scientific research

152 worldwide, the relative ease of identification (butterflies) and the role that

153 non-drosophilid Diptera play as disease vectors.

We found the five most dominant response variables to climate change were

155 changes in abundance, distribution/ range shift, interactions, assemblage

156 composition, and phenology (Figure 7a). For all response variables (except

157 'non-specific'), data collection was most common, followed by modelling studies,

158 reviews, desktop studies and no theme studies. This trend did not continue for

159 studies on interactions, no theme ('non-specific'), and behaviour where review

160 studies were more common than modelling studies (Figure $7 \mathrm{~b}$ and $\mathrm{c}$ ). When

161 response variables were assessed in relation to the 10 top ranked Orders (Figure 8a

162 and b) studies comparing most of the response variables were most studied in the

163 Lepidoptera, Diptera, Multiple taxa, and Coleoptera. 
This analysis of current climate change research, specifically on insect groups and the type of information gathered indicates that the Orders Lepidoptera, Diptera, Orthoptera and Collembola are relatively well studied, whilst Coleoptera and Hymenoptera are relatively understudied relative to the number of species currently identified in each Order. There is a general tendency for research publications to focus on population changes in abundance and distribution/ range shift, and relatively fewer focusing on biological reasons for these changes. Fundamental biological research areas such as physiology, behaviour, and genetics, are relatively depauperate in the assessment of insect responses to climate change (14\% of publications together in total), and this gap could be limiting the ability for broad generalisations to be developed quickly (Chown et al. 2010). The importance of insect physiology and behaviour in the distribution and abundance of species has been known for a long time (Andrewartha \& Birch 1954), as has the strong association between ecology and physiology (Chown, Gaston \& Robinson 2004; Gaston et al. 2009). Understanding responses to climate change is a crucial area where knowledge across disciplines is vital (Williams et al. 2008). This information is required to identify how scientists can build mechanistic models of responses to climate change (Angilletta \& Sears 2011), as well as integrate this information into broader models crossing trophic levels (Mitchell \& Angilletta 2009). Furthermore, the integration of models into data collection research studies would also assist in assessing insect responses to climate change (Angilletta \& Sears 2011).

Climate change studies with insects have primarily focused on changes in abundance, and change in the distribution of species, as these are the easiest measures of change to test, especially in field conditions. However, populations may have annual fluctuations and keep within their distribution, but be impacted in other 
189 ways including a reduction in fitness and population viability (Lane et al. 2012).

190 Surviving insects may be of a particular genotype, or have been pushed closer to

191 their physiological tolerance. An analogous impact of this can be seen in agricultural

192 production areas where prophylactic sprays have been used to control insects, killing

193 off the majority of individuals, but a small number of a resistant individuals survive

194 (Gray, Ratcliffe \& Rice 2009). The resistant animals then increase in numbers and

195 return to high abundances over a relative short time (a few seasons in some cases)

196 with higher resistance to the chemical spray, but with a much reduced genotypic

197 variation (Page \& Horne 2012). From a climate change perspective, more thermally

198 tolerant populations within a species may be more resistant than others (Elmes et al.

199 1999; Nielsen, Elmes \& Kipyatkov 1999; Mueller et al. 2011). Such population

200 changes exemplifies the critical role that genetic and genomic assessments of

201 population responses to climate change play (e.g. Zakharov \& Hellmann 2008;

202 Telonis-Scott et al. 2012)

Physiological tolerances of thermal extremes vary for different species and for

204 different species across their range. Indeed even within a population, males and

205 females may exhibit different responses to thermal stress. A non-insect example of

206 this is the pseudoscorpion Cordylochernes scorpioides (Zeh et al. 2012) put under a

$2073.5^{\circ} \mathrm{C}$ temperature stress (compared to average temperature) using a split brood

208 experiment; the higher temperature reduced development time but also reduced

209 size, particularly of males and thus reducing sexual dimorphism. The males

210 produced $45 \%$ less sperm and females failed to produce embryos. However, when

211 males were re-acclimated back to the ambient temperature seven days before

212 mating, sperm count did not change. However, females which did not produce

213 embryos at high temperature were able to produce embryos after a seven day 
214 acclimation at control temperatures, and no females moved from the control

215 temperature to the high temperature became gravid with seven days exposure. Such

216 cases exhibit the crucial importance of understanding fundamental biology of

217 organisms if we are to make accurate predictions about population responses to a

218 rapidly changing climate.

Ectotherms may also stay within their habitat when there are a variety of

220 microhabitats to choose from. Most species modelling is based on average

221 temperature readings that are not directly in the habitat of the organism being

222 studied. For example, WORLDCLIM derived climate data (Hijmans et al. 2005) are

223 from weather stations located a few metres off the ground, in open, clear

224 microhabitats not directly associated with the primary habitat of organisms.

225 Therefore the use of such data may lead to very different interpretation than from

226 data collected from an organism's habitat. For example, the warming tolerance (WT)

227 and thermal safety margins (TSM) of the meat ant Iridomyrmex purpueus (Andrew et

228 al. unpublished data) based on weather station annual average temperatures were

$22925.8^{\circ} \mathrm{C}(\mathrm{WT})$ and $13.78^{\circ} \mathrm{C}(\mathrm{TSM})$. These values declined to $19.5^{\circ} \mathrm{C}$ and $7.51^{\circ} \mathrm{C}$ when

230 based on summer average temperatures, and declined further to $7.81^{\circ} \mathrm{C}$ (WT) and

$231-4.2^{\circ} \mathrm{C}(\mathrm{TSM})$ when based on temperatures recorded at the nest site during summer

232 between 10am and 4pm when the ants are under the highest thermal stress.

There is a fundamental difficulty in interpreting biological responses to rapid

234 climate change when the biology of species is not well known and experiments are

235 only carried out over short time periods. Most studies which are considered long

236 term usually have no more than 10 years of accumulated data, with older

237 morphological and potential DNA data for single species found in museum 
238 collections (Lister 2011). Very few directly comparable collected datasets have data

239 constantly recorded over multiple decades and centuries, keeping consistent

240 methodologies, collecting sufficient data, or sampling comprehensively across all

241 biota (Magurran et al. 2010). Two of the most comprehensive datasets we currently

242 have for insects are from Rothamstead in the UK, and of locust outbreaks in China.

243 In Rothamstead, moth records date back to 1933 with light traps at 80 sites around

244 the UK, and aphid populations have been monitored via suction traps since 1964

245 when a national network of sixteen aphid collection sites were dispersed throughout

246 the UK (Harrington \& Woiwod 2007). In China, migratory locusts records were

247 haphazardly collected over a 1,910 year period (Tian et al. 2011) from historical

248 documents. The general lack of long-term datasets globally and across taxa

249 challenges our ability to make strong comparative generalisations about species

250 responses and the biological impacts of climate change.

251

252

253

254

255

256

257

258

259

260

261

262

It is clear from the current assessment that changes in abundance and range/ distribution shift of single species are the main focus in insect responses to climate change. Therefore for future studies, it is vital that researchers identify the type of habitat they are working in to continue this type of work ('non-specified' habitats accounted for $28 \%$ of publications in this assessment). We also recommend an emphasis on the causes of these changes is required by the assessment of insect population dynamics, ecology, physiology, behaviour, and genetic/ genomic analyses. Many species will more likely adapt to a changing climate in-situ, and what impact this has on their recruitment and population dynamics is unclear. When single species studies are conducted it would be instructive to explore modeled predictions in research papers to identify the impacts of a changing climate on insects. In its most simplistic form species predictions could be undertaken using species 
263

264

265

266

267

268

269

270

271

272

273

274

275

276

277

278

279

280

281

282

283

284

285

286

287

distribution modeling or vulnerability indices (Rowland, Davison \& Graumlich 2011).

When assemblages are assessed then community change predictions would also be

of use. This can be done using relationship changes between trophic levels of species and competition among species using existing tools such as game theory

(Mitchell \& Angilletta 2009), or using statistical relationships based on changes in assemblage composition (fitting predictive models in mvabund; Wang et al. 2012) or functional traits (Brown et al. in review).

Even today we are still just beginning to understand how insects will respond to a rapidly changing climate, but the current trends of publications give a good basis for how we are attempting to assess insect responses. There is a crucial need for a broader study of ecological, behavioural, physiological and life history responses to be addressed across a greater range of geographic locations, particularly Asia, Australia/ Oceania, Africa, and South America, and in areas of high human population growth and habitat modification.

We are not advocating that research should be done on under-represented taxa to merely equilibrate the research done on each taxa relative to the number of identified species. A wider range of taxa should be studied to attempt to identify how generalised trends in response to climate change are across taxa. This also exemplifies the need for understanding the role of phylogenetic relatedness and functional/ morphological traits across a range of species and within/ among communities (Yates \& Andrew 2011; Srivastava et al. 2012; Best, Caulk \& Stachowicz 2013). Future work should consider these issues critically, and some exemplar questions to pose include: Are the range movements measured in European butterfly's in native habitats, an umbrella response to other more-poorly understood taxa from Europe (including Coleoptera, and Hymenoptera) from those 
288 same habitats? Is this trend applicable in other parts of the world? Will individual 289 species, taxa or functional groups respond in a highly variable way within and among 290 regions? Rigorous testing of such predictions are required globally to develop a 291 better understanding of biotic responses to climate change..

292

293

Acknowledgements: Graham Hall commented on an earlier version of the 294 manuscript.

295

296 
Andrew NR (2013) Population dynamics of insect populations: impacts of a changing climate In: Rohde K, ed. The Balance of Nature and Climate Change: Cambridge University Press, 311-324.

Andrew NR, Hart RA \& Terblanche JS (2011) Limited plasticity of low temperature tolerance in an Australian cantharid beetle Chauliognathus lugubris. Physiological Entomology. 36: 385-391.

Andrew NR \& Hughes L (2004) Species diversity and structure of phytophagous beetle assemblages along a latitudinal gradient: predicting the potential impacts of climate change. Ecological Entomology. 29: 527-542.

Andrew NR \& Hughes L (2005) Arthropod community structure along a latitudinal gradient: implications for future impacts of climate change. Austral Ecology. 30: $281-297$.

Andrew NR \& Terblanche JS (2013) Chapter 16: Insects. In: Salinger J, ed. Climate of Change: Living in a Warmer World, Auckland: David Bateman Ltd

Andrewartha HG \& Birch LC (1954) The Distribution and Abundance of Animals. University of Chicago Press, Chicago.

Angilletta MJ (2009) Thermal Adaptation: A Theoretical and Empirical Synthesis. Oxford University Press, New York.

Angilletta MJ \& Sears MW (2011) Coordinating theoretical and empirical efforts to understand the linkages between organisms and environments. Integrative and Comparative Biology. 51: 653-661.

Best RJ, Caulk NC \& Stachowicz JJ (2013) Trait vs. phylogenetic diversity as predictors of competition and community composition in herbivorous marine amphipods. Ecology Letters. 16: 72-80. 
Brereton T, Roy D, Middlebrook I, Botham M \& Warren M (2011) The development of butterfly indicators in the United Kingdom and assessments in 2010. Journal of Insect Conservation. 15: 139-151.

Brown AM, Warton DI, Andrew NR, Binns M, Cassis G \& Gibb H (in review) A model-based approach to the fourth-corner problem. Ecology.

Burthe S, Butler A, Searle KR, Hall SJG, Thackeray SJ \& Wanless S (2011) Demographic consequences of increased winter births in a large aseasonally breeding mammal (Bos taurus) in response to climate change. Journal of Animal Ecology. 80: 1134-1144.

Chown SL, Gaston KJ \& Robinson D (2004) Macrophysiology: large-scale patterns in physiological traits and their ecological implications. Functional Ecology. 18: 159-167.

Chown SL, Hoffmann AA, Kristensen TN, Angilletta MJ, Stenseth NC \& Pertoldi C (2010) Adapting to climate change: a perspective from evolutionary physiology. Climate Research. 43: 3-15.

Clusella-Trullas S, Terblanche JS, Blackburn TM \& Chown SL (2008) Testing the thermal melanism hypothesis: a macrophysiological approach. Functional Ecology. 22: 232-238.

Cranston PS (2010) Insect biodiversity and conservation in Australasia. Annual Review of Entomology. 55: 55-75.

Dunn RR (2005) Modern insect extinctions, the neglected majority. Conservation Biology. 19: 1030-1036.

Elmes GW, Wardlaw JC, Nielsen MG, Kipyatkov V, Lopatina EB, Radchenko AG \& Barr B (1999) Site latitude influences on respiration rate, fat content and the ability of worker ants to rear larvae: a comparison of Myrmica rubra 
(Hymenoptera: Formicidae) populations over their European range. European Journal of Entomology. 96: 117-124.

349

350

351

352

353

354

355

356

357

358

359

360

361

362

363

364

365

366

367

368

369

370

Gaston KJ, Chown SL, Calosi P, Bernardo J, Bilton DT, Clarke A, Clusella-Trullas S, Ghalambor CK, Konarzewski M, Peck LS, Porter WP, Portner HO, Rezende EL, Schulte PM, Spicer JI, Stillman JH, Terblanche JS \& van Kleunen M (2009) Macrophysiology: A Conceptual Reunification. American Naturalist. 174: 595-612.

Gray ME, Ratcliffe ST \& Rice ME (2009) The IPM paradigm: concepts, strategies and tactice. Cambridge University Press, Cambridge.

Gullan PJ \& Cranston PS (2010) The Insects: An Outline of Entomology, Fourth edn. Blackwell Publishing, Carlton.

Harrington R \& Woiwod I (2007) Foresight from hindsight: the Rothamsted insect survey. Outlooks on Pest Management. 18: 9-14.

Hijmans RJ, Cameron SE, Parra JL, Jones PG \& Jarvis A (2005) Very high resolution interpolated climate surfaces for global land areas. International Journal of Climatology. 25: 1965-1978.

Hoffmann AA, Sørensen JG \& Loeschcke V (2003) Adaptation of Drosophila to temperature extremes: bringing together quantitative and molecular approaches. Journal of Thermal Biology. 28: 175-216.

Hughes L (2003) Climate change and Australia: Trends, projections, and impacts. Austral Ecology. 28: 423-443.

IPCC (2007) Summary for Policymakers. In: Solomon S, Qin D, Manning M, Chen Z, Marquis M, Averyt KB, M.Tignor \& Miller HL, ed. Climate Change 2007: The Physical Science Basis. Contribution of Working Group I to the Fourth 
373

Juroszek P \& von Tiedemann A (2012) Plant pathogens, insect pests and weeds in a changing global climate: a review of approaches, challenges, research gaps, key studies and concepts. The Journal of Agricultural Science. FirstView: $1-26$.

Kearney M, Porter WP, Williams C, Ritchie S \& Hoffmann AA (2009) Integrating biophysical models and evolutionary theory to predict climatic impacts on species' ranges: the dengue mosquito Aedes aegypti in Australia. Functional Ecology. 23: 528-538.

Keatley MR, Fletcher TD, Hudson IL \& Ades PK (2002) Phenological studies in Australia: potential application in historical and future climate analysis. International Journal of Climatology. 22: 1769-1780.

Kellermann V, Van Heerwaarden B, Sgrò CM \& Hoffmann AA (2009) Fundamental evolutionary limits in ecological traits drive Drosophila species distributions. Science. 325: 1244-1246.

Lane JE, Kruuk LEB, Charmantier A, Murie JO \& Dobson FS (2012) Delayed phenology and reduced fitness associated with climate change in a wild hibernator. Nature. 489: 554-557.

Lister AM (2011) Natural history collections as sources of long-term datasets. Trends in Ecology and Evolution. 26: 153-154.

Loarie SR, Duffy PB, Hamilton H, Asner GP, Field CB \& Ackerly DD (2009) The velocity of climate change. Nature. 462: 1052-1055.

Magurran AE, Baillie SR, Buckland ST, Dick JM, Elston DA, Scott EM, Smith RI, Somerfield PJ \& Watt AD (2010) Long-term datasets in biodiversity research 
and monitoring: assessing change in ecological communities through time. Trends in Ecology and Evolution. 25: 574-582.

398 399

400 401 402 403 404 405 406 407 408 409 410 411 412 413

Mitchell WA \& Angilletta MJ (2009) Thermal games: frequency-dependent models of thermal adaptation. Functional Ecology. 23: 510-520.

Moore PJ, Thompson RC \& Hawkins SJ (2011) Phenological changes in intertidal con-specific gastropods in response to climate warming. Global Change Biology. 17: 709-719.

Mueller UG, Mikheyev AS, Hong E, Sen R, Warren DL, Solomon SE, Ishak HD, Cooper M, Miller JL, Shaffer KA \& Juenger TE (2011) Evolution of cold-tolerant fungal symbionts permits winter fungiculture by leafcutter ants at the northern frontier of a tropical ant-fungus symbiosis. Proceedings of the National Academy of Sciences of the United States of America. Early Edition.

Nielsen MG, Elmes GW \& Kipyatkov VE (1999) Respiratory Q10 varies between populations of two species of Myrmica ants according to the latitude of their sites. Journal of Insect Physiology. 45: 559-564.

Page J \& Horne P (2012) Controlling Invertebrate Pests in Agriculture. CSIRO, Collingwood, Victoria.

Parmesan C (2006) Ecological and evolutionary responses to recent climate change. Annual Review of Ecology Evolution and Systematics. 37: 637-669.

Parmesan C (2007) Influences of species, latitudes and methodologies on estimates of phenological response to global warming. Global Change Biology. 13: 1860-1872.

Parmesan C \& Yohe G (2003) A globally coherent fingerprint of climate change impacts across natural systems. Nature. 421: 37-42. 
420 Peñuelas J, Filella I \& Comas P (2002) Changed plant and animal life cycles from

421

422

423

424

425

426

427

428

429

430

431

432

433

434

435

436

437

438

439

440

441

442

443

1952 to 2000 in the Mediterranean region. Global Change Biology. 8: 531-544.

Price PW, Denno RF, Eubanks MD, Finke DL \& Kaplan I (2011) Insect Ecology: Behavior, Populations and Communities. Cambridge University Press, Cambridge

Rafferty NE \& Ives AR (2011) Effects of experimental shifts in flowering phenology on plant-pollinator interactions. Ecology Letters. 14: 69-74.

Root TL, Price JT, Hall KR, Schneider SH, Rosenzweig C \& Pounds JA (2003) Fingerprints of global warming on wild animals and plants. Nature. 421: 57-60. Rowland EL, Davison JE \& Graumlich LJ (2011) Approaches to evaluating climate change impacts on species: a guide to initiating the adaptation planning process. Environmental Management. 47: 322-337.

Srivastava DS, Cadotte MW, MacDonald AAM, Marushia RG \& Mirotchnick N (2012) Phylogenetic diversity and the functioning of ecosystems. Ecology Letters. 15: 637-648.

Telonis-Scott M, Gane M, DeGaris S, Sgró CM \& Hoffmann AA (2012) High resolution mapping of candidate alleles for desiccation resistance in Drosophila melanogaster under selection. Molecular Biology and Evolution. 29: $1335-1351$.

Tian H, Stige LC, Cazelles B, Kausrud KL, Svarverud R, Stenseth NC \& Zhang Z (2011) Reconstruction of a 1,910-y-long locust series reveals consistent associations with climate fluctuations in China. Proceedings of the National Academy of Sciences. 108: 14521-14526. 
Walther G-R, Post E, Convey P, Menzel A, Parmesan C, Beebee TJC, Fromentin J-M, Hoegh-Guldberg O \& Bairlein F (2002) Ecological responses to recent climate change. Nature. 416: 389-395.

Wang Y, Naumann U, Wright ST \& Warton DI (2012) mvabund - an R package for model-based analysis of multivariate abundance data.

Williams SE, Shoo LP, Isaac JL, Hoffmann AA \& Langham G (2008) Towards an integrated framework for assessing the vulnerability of species to climate change. PLoS Biology. 6: e325.

Wilson RJ \& Maclean IMD (2011) Recent evidence for the climate change threat to Lepidoptera and other insects. Journal of Insect Conservation. 15: 259-268.

Woodward FI (1987) Stomatal numbers are sensitive to increases in CO2 from pre-industrial levels. Nature. 327: 617-618.

Yates M \& Andrew NR (2011) Comparison of ant community composition across different land-use types: assessing morphological traits with more common methods. Australian Journal of Entomology. 50: 118-124.

Yeates DK, Harvey MS \& Austin AD (2003) New estimates for terrestrial arthropod species-richness in Australia. Records of the South Australian Museum Monograph Series. 7: 231-241.

Zakharov EV \& Hellmann JJ (2008) Genetic differentiation across a latitudinal gradient in two co-occurring butterfly species: Revealing population differences in a context of climate change. Molecular Ecology. 17: 189-208.

Zborowski P \& Storey R (2010) A Field Guide to Insects in Australia, 3rd Edition edn. Reed New Holland, Sydney.

Zeh JA, Bonilla MM, Su EJ, Padua MV, Anderson RV, Kaur D, Yang DS \& Zeh DW (2012) Degrees of disruption: Projected temperature increase has 
471

472 


\section{Figure 1}

Number of publications assessing the impact of climate change on insects from 1985 to 2012. A star is shown for 2012 as it only includes papers up to August 2nd.

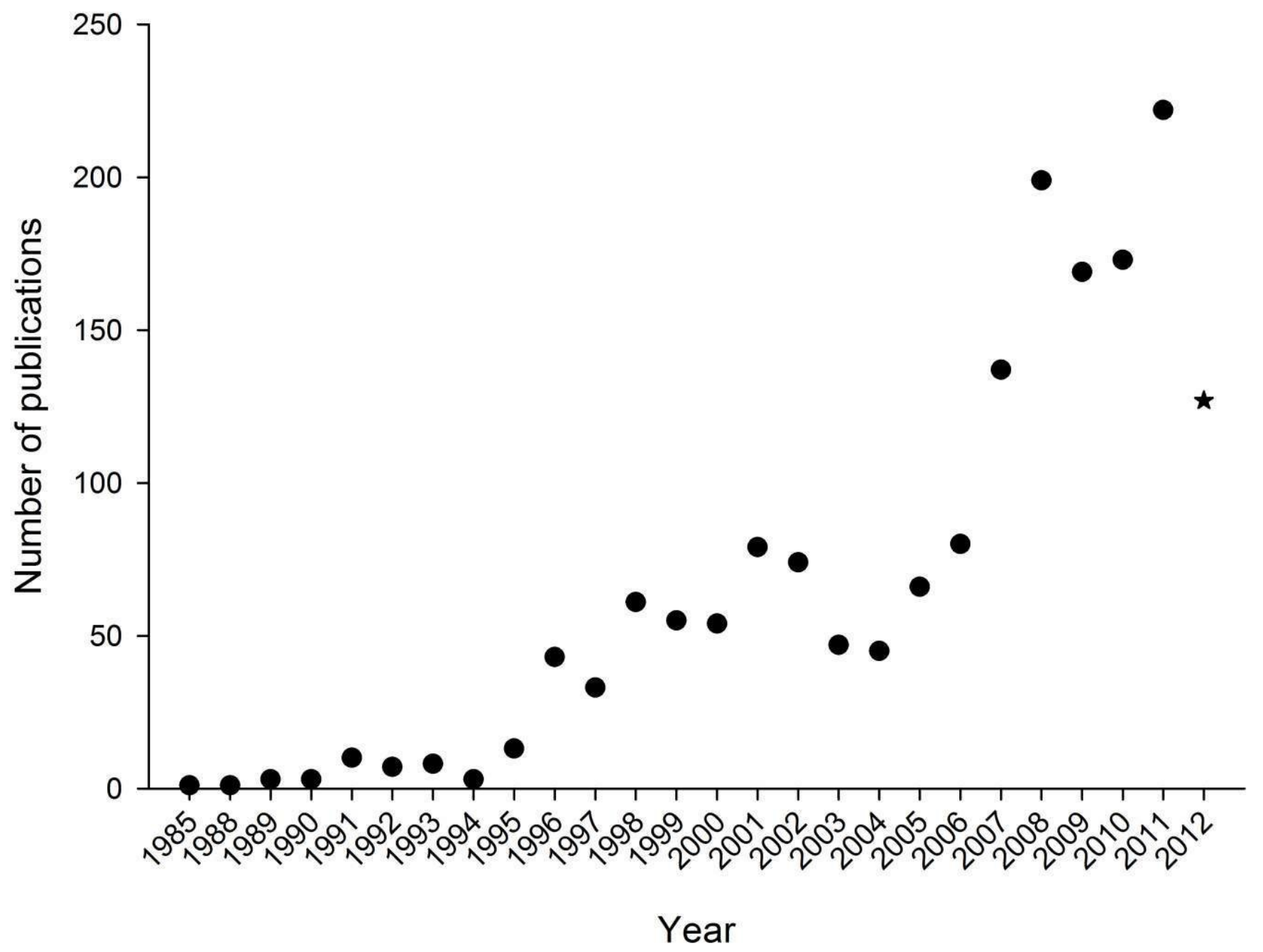




\section{Figure 2}

a) Proportion of published papers and estimate number of species within the top 18 orders studied. b) number of published papers in each of the top 18 order studies, and publication type. 

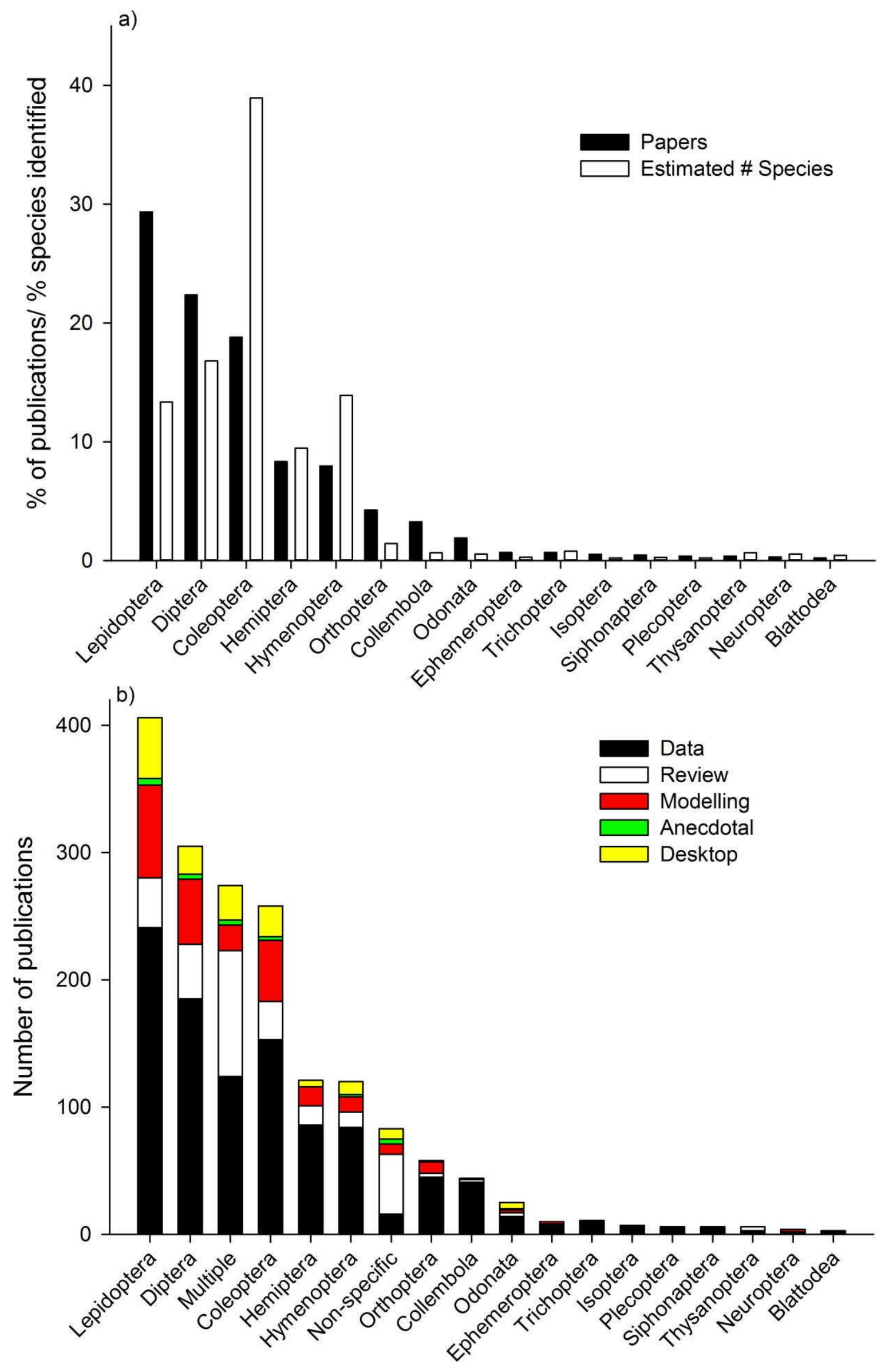


\section{Figure 3}

Number of published studies assessing the impacts of climate change on the numerically top insect Orders (based on number of publications) from different global regions. Regions based on Table 1. 


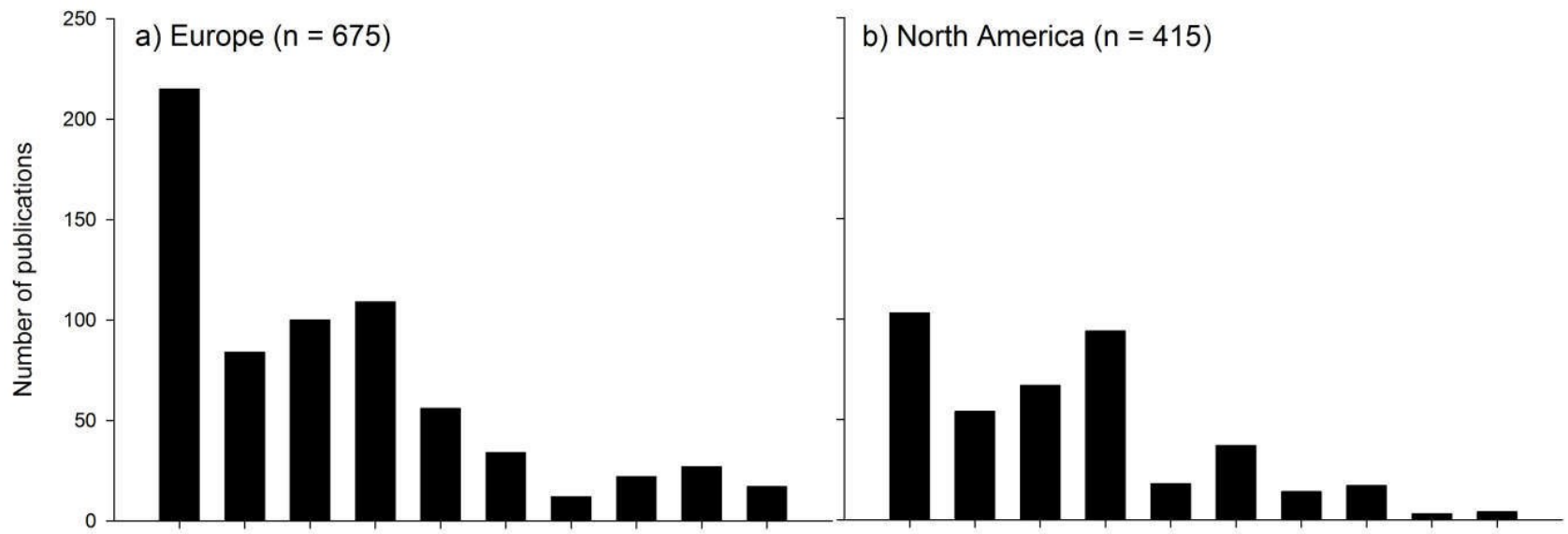

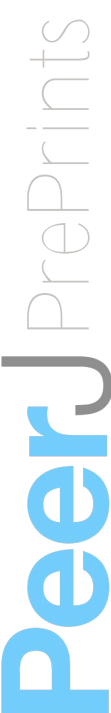
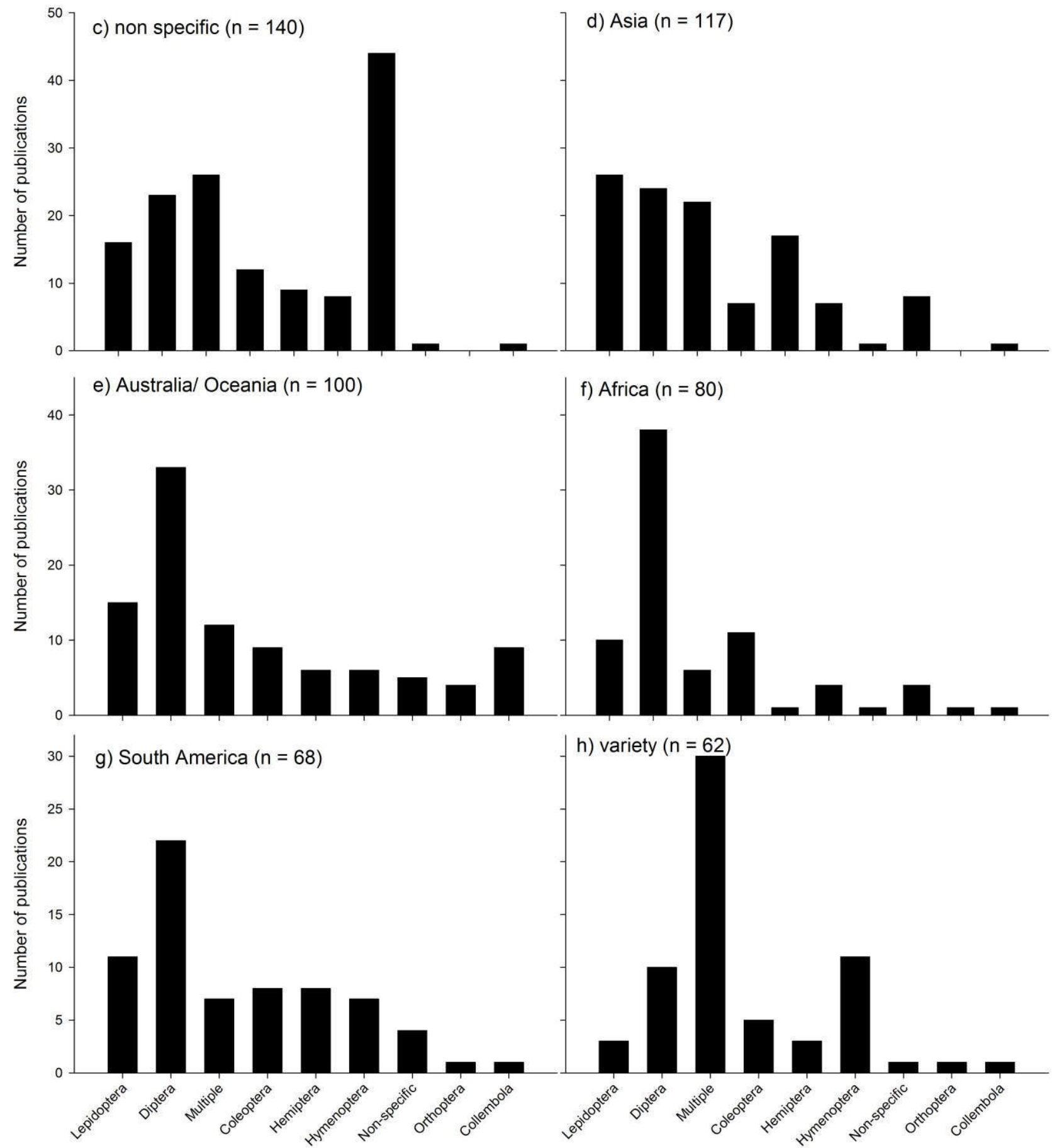


\section{Figure 4}

Number of publications addressing different climate change factors by a) different assemblages types; b) publication type and c) habitat type. 


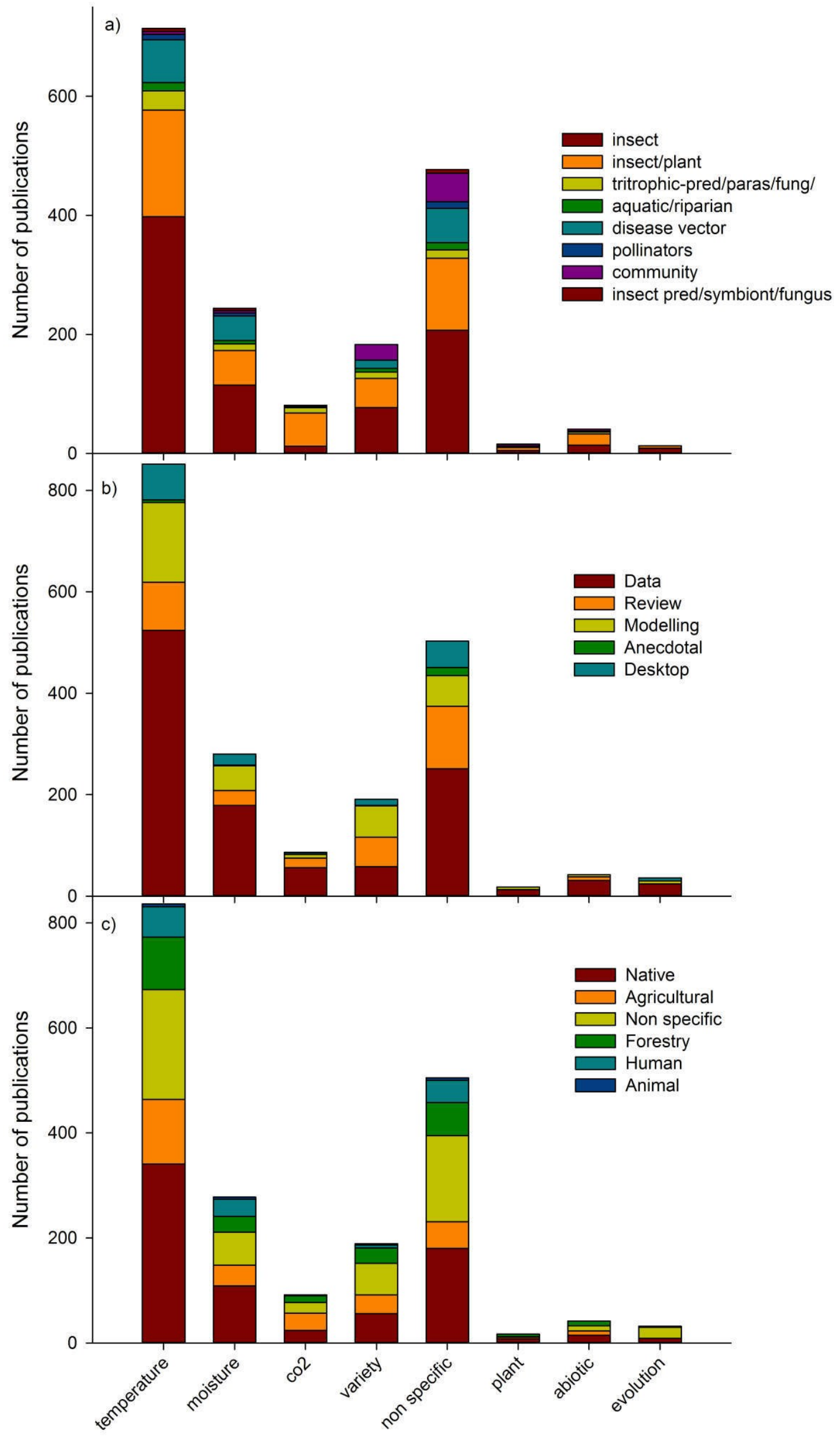




\section{Figure 5}

How insect responses to climate change have been recorded in publications between 1985 and 2012. Four groups allocated (A $\square$ D) based on number of publications in each response group.

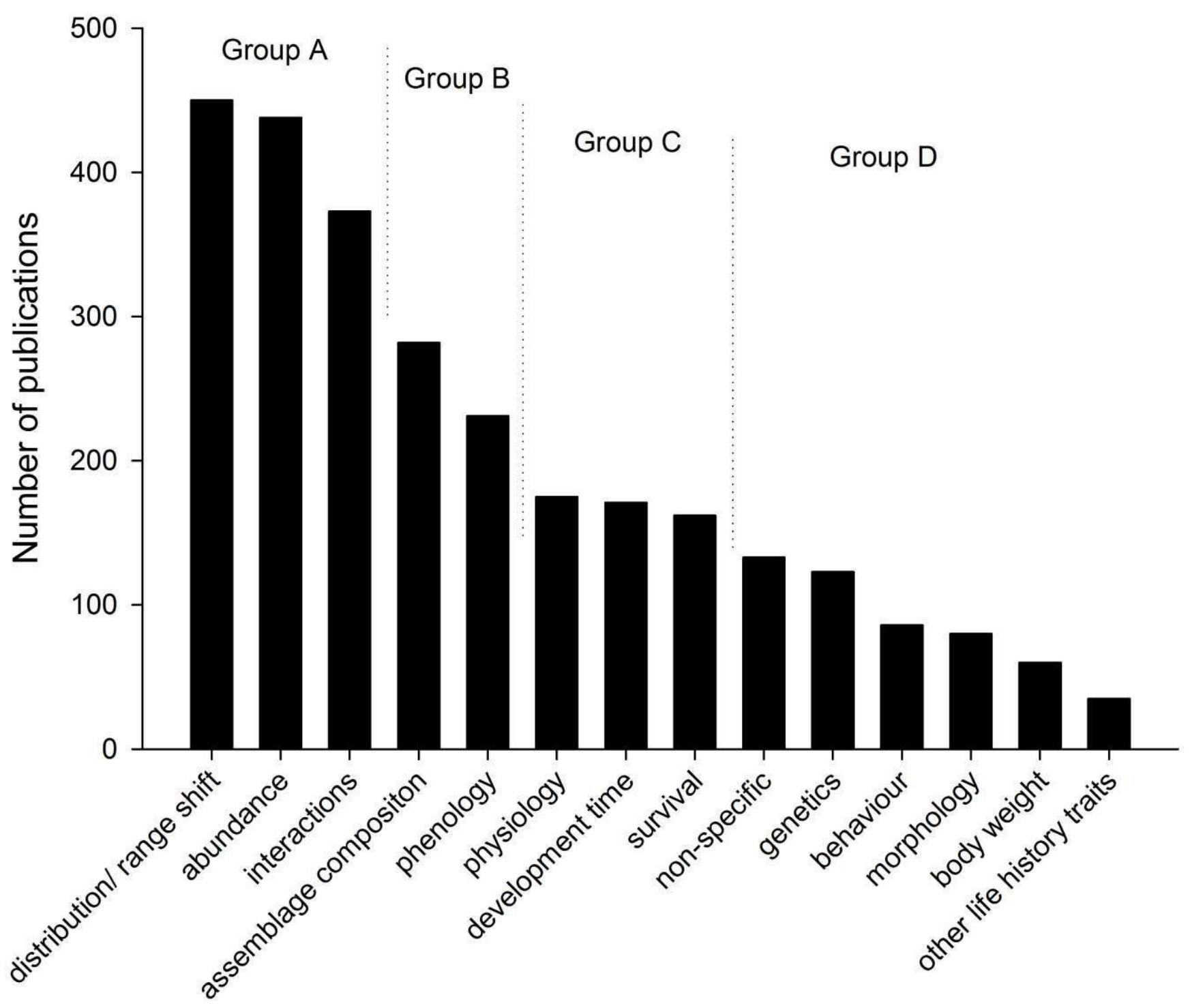




\section{Figure 6}

Number of publications produced for each of the dominant Orders in different habitats. Habitats based on Table 1. 

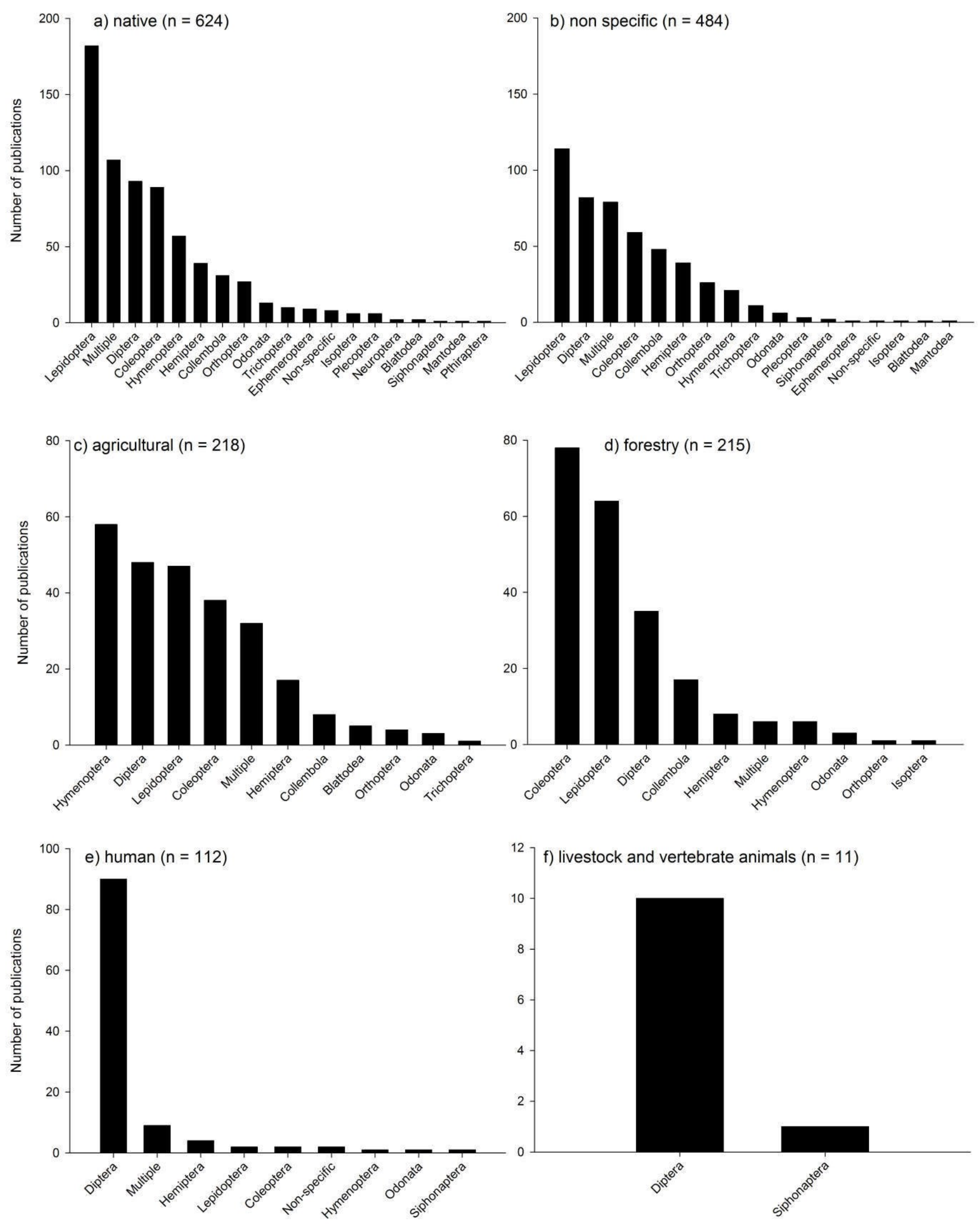


\section{Figure 7}

Publication type and insect response variable recorded in publications. 


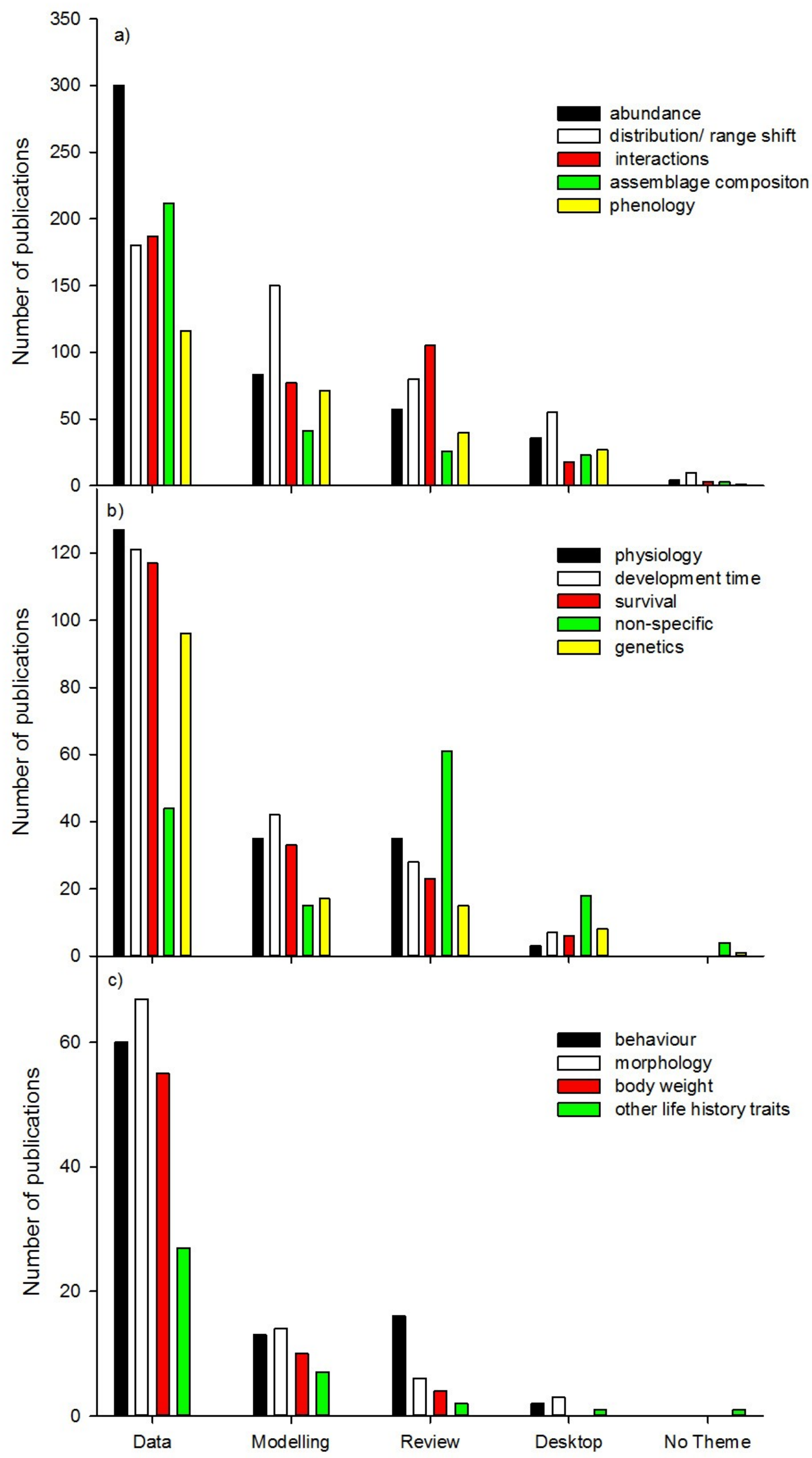




\section{Figure 8}

Number of publications based on the top 10 ranked Orders (based on number of publications) and response variable of taxa studied by authors. Response variables based on Table 1 . 

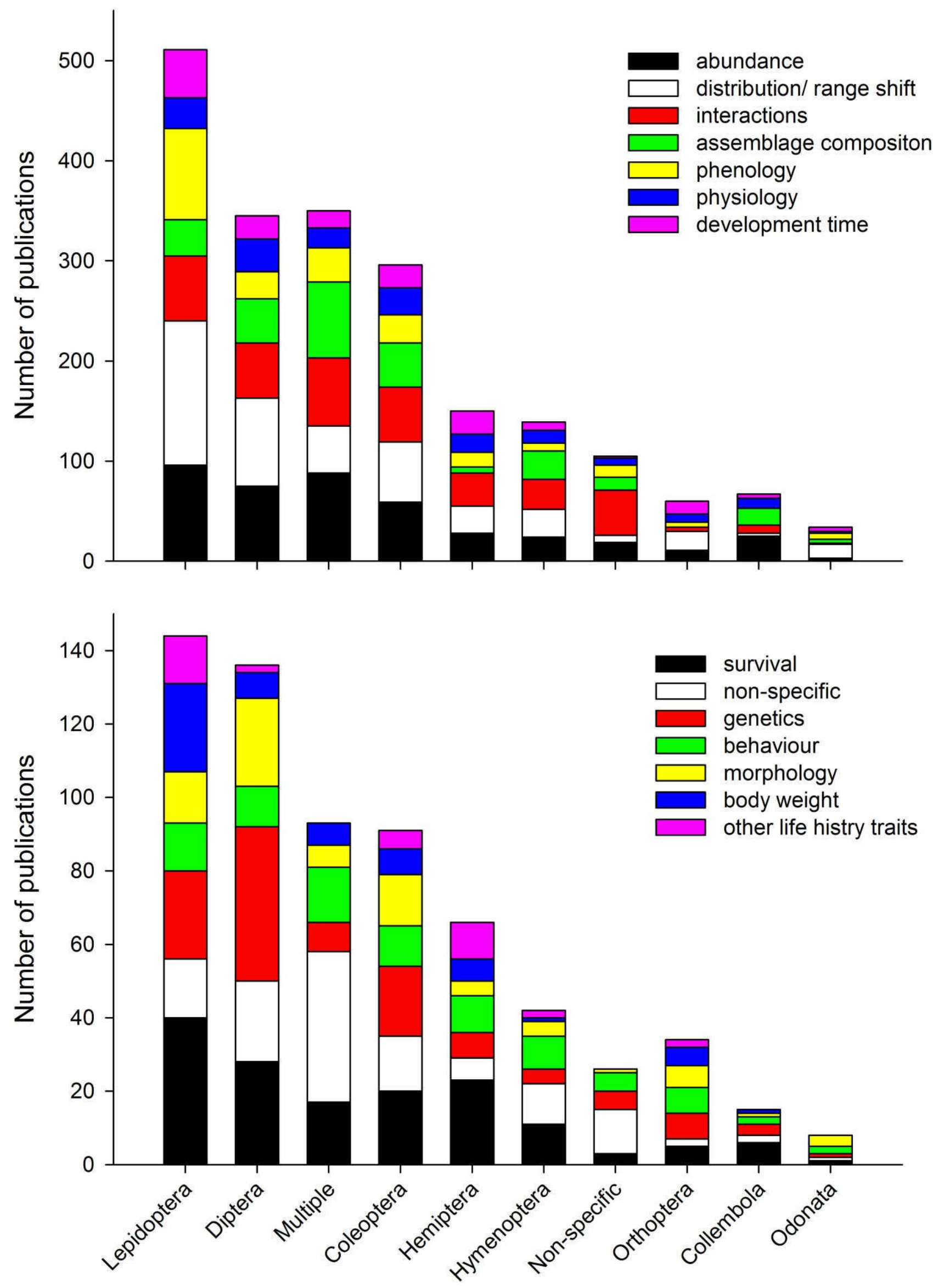


\section{Table $\mathbf{1}_{\text {(on next page) }}$}

Categories given to each study for data type, region, the main climatic drivers, the type of information that authors collected and presented in their results, and the habitat sampled. 
Table 1. Categories given to each study for data type, region, the main climatic drivers that authors identified, the type of information that authors collected and presented in their results, and the habitat in which the study was carried out.

\begin{tabular}{|c|c|c|c|c|}
\hline Data type & Region & Climatic drivers & Information & Habitat \\
\hline $\begin{array}{l}\text { Data only } \\
\text { Data and } \\
\text { modelling } \\
\text { Desktop } \\
\text { Modelling } \\
\text { Review } \\
\text { No Theme }\end{array}$ & $\begin{array}{l}\text { Antarctic } \\
\text { Arctic } \\
\text { Asia } \\
\text { Australia/Oceania } \\
\text { Europe } \\
\text { Global } \\
\text { Middle East } \\
\text { New World } \\
\text { Non-specific } \\
\text { North America } \\
\text { South America } \\
\text { Tropics } \\
\text { Variety }\end{array}$ & $\begin{array}{l}\text { Temperature } \\
\text { (Temp) } \\
\text { Moisture } \\
\text { Temp and Moist } \\
\text { Evolution } \\
\text { Carbon dioxide } \\
\text { (CO2) } \\
\text { Temp and CO2 } \\
\text { Variety } \\
\text { Non specific } \\
\text { Fire } \\
\text { CO2 and Ozone } \\
\text { UVB } \\
\text { Others }\end{array}$ & $\begin{array}{l}\text { Abundance } \\
\text { Distribution/ } \\
\text { range shift } \\
\text { Interactions } \\
\text { Assemblage } \\
\text { composition } \\
\text { Phenology } \\
\text { Development } \\
\text { time } \\
\text { Survival } \\
\text { Physiology } \\
\text { Non-specific } \\
\text { Genetics/ } \\
\text { Genomics } \\
\text { Behaviour } \\
\text { Morphology } \\
\text { Body weight } \\
\text { Other life } \\
\text { history traits }\end{array}$ & $\begin{array}{l}\text { Native } \\
\text { Agricultural } \\
\text { Native/ } \\
\text { Agricultural } \\
\text { Forestry } \\
\text { Human/ } \\
\text { Domestic } \\
\text { Animal } \\
\text { Non-specifi } \\
\text { c }\end{array}$ \\
\hline
\end{tabular}




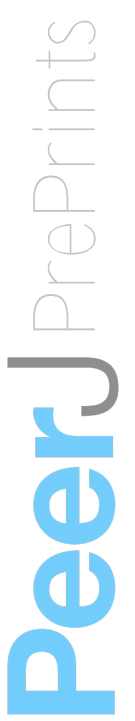

